\title{
Choosing Wisely (and carefully) Canada
}

everal medical associations joined with the Canadian Medical Association in the launch of a new campaign, Choosing Wisely Canada (CWC; www.choosingwiselycanada.org). Two surgical groups were in the first wave of participants - the Canadian Association of General Surgeons (CAGS) and the Canadian Orthopaedic Association (COA). The CWC initiative is aimed at helping physicians and patients engage in conversations about tests, treatments and procedures.

The CWC campaign seems like a good initiative in terms of promoting a national platform for communication about health care in Canada. The federal government has pulled out of the health care business and has left a vacuum at the top. The transfer payments aimed at health are falling in value and have really become a small portion of overall health spending nationally. A lack of national data management in big-ticket areas like trauma care and other efforts show that the federal government is leaving the medical field with no clear policy leader. We need to have more meaningful and uninterrupted dialogue about all health care going forward. So the CWC effort seems as good a place as any to start.

To promote communication between patients and physicians, we will have to avoid bickering and pointing fingers when choosing what procedures we need to examine. In the reality of a closed envelope of health funding it will be very tempting for some specialties to look over into another group's piece of the pie and say we should cut spending there. Although some of these observations may be correct, this is not what CWC is meant to accomplish. Our neighbours to the south have already been down the road of choosing wisely, but many of the medical groups chose to point out other doctors' procedures that may not be appropriate and minimized their own specialties' needs for introspection. This was not the visualized driver behind CWC. However, this may be the road that the initiative will travel in Canada as well, although it is not necessarily a bad concept if it opens up constructive communication among specialties to examine the processes in health care.

The other caveat is that, although CWC is an effort to improve communication, the information and comments within the group could potentially be used by provincial administrations to curtail medical acts. This would not be a desirable effect. It is not up to the government, as an often absentee landlord, to determine what procedures physicians perform. This should fall solidly into continuing medical education within each national specialty society and provincial physician organization. It is up to the respective medical education programs of the leadership organizations, such as the COA and CAGS, to determine appropriate treatments. There are limited indications for some procedures, but this is to be determined by the treating physician as the person with the best grasp of indications for medical acts.

The CWC initiative will help us open a dialogue and that dialogue should not be among dissenting medical societies or provincial health administrations but instead between the physicians and their patients. We need to be careful in the implementation so that is what actually happens.

Edward J. Harvey, MD

Coeditor, Canadian fournal of Surgery

Competing interests: None declared.

DOI: $10.1503 /$ cjs.005214 